Frans B. Plötz

Martin Kneyber

Marc van Heerde

Dick Markhorst

\section{Traumatic pediatric brain injury and intracranial pressure monitoring: does it really improve outcome?}

Received: 24 November 2006

Accepted: 27 March 2007

Published online: 25 April 2007

(C) Springer-Verlag 2007

Sir: We read with great interest the contribution by Morris et al. [1]. The authors and the United Kingdom Paediatric Traumatic Brain Injury (TBI) Study Group need to be congratulated on setting up this databank, providing useful information regarding severe traumatic brain injury in children. The objective of the study was to identify factors associated with the use of intracranial pressure (ICP) monitoring and to determine what ICP-targeted therapies are being used in children with severe TBI. The authors observed that ICP monitoring was undertaken in $45 \%$ of cases, and this increased to $59 \%$ in those with an emergency room Glasgow Coma Score of 8 or below. First-tier ICP targeted therapy was found to differ substantially between centers. Finally, the authors advocated the use of ICP monitoring and targeted therapy and concluded that less variation in management could have a beneficial effect on outcome.
Despite widespread recommendation by experts in the field there is no sound evidence that monitoring of ICP and ICP-targeted therapy improve outcome [2]. Recently a retrospective cohort study in two level I trauma centers in The Netherlands from 1996 to 2001 determined the effect of ICP-targeted therapy on functional outcome in severely head-injured adults [3]. In center A therapeutic interventions were based on clinical observations and computed tomography findings, whereas in center B management was aimed at maintaining ICP below $20 \mathrm{mmHg}$ and CPP above $70 \mathrm{mmHg}$. In-hospital mortality rate was $41(34 \%)$ vs. 69 (33\%, $p=0.87)$. The odds ratio for a more favorable functional outcome following ICP/CPP-targeted therapy was 0.95 (95\% confidence interval 0.62-1.44). This result remained after adjustment for potential confounders. Sedatives, vasopressors, mannitol, and barbiturates were much more frequently used in center B (all $p=<0.01)$.

In this respect it would have been very interesting if the authors had provided additional information on outcome between the groups, in particular for patients with an emergency room Glasgow Coma Score of 8 or below, for example, on whether was there a difference in death due to incarnation, in-hospital mortality, and neurological outcome. This additional information would provide at least some indication whether ICP-targeted therapy improves mortality and neurological outcome.

\section{References}

1. Morris KP, Forsyth RJ, Parslow RC, Tasker RC, Hawley CA (2006) Intracranial pressure monitoring complicating severe traumatic brain injury in childrens: monitoring and management. Intensive Care Med 32:1606-1612

2. Adelson PD, Bratton SL, Carney NA, Chesnut RM, du Coudray HE, Goldstein B, Kochanek PM, Miller HC, Partington MD, Selden NR, Warden CR, Wright DW (2003) Guidelines for the acute medical management of severe traumatic brain injury in infants, children, and adolescents. Chapter 5. Indications for intracranial pressure monitoring in pediatric patients with severe traumatic brain injury. Pediatr Crit Care Med 4:S19-S24

3. Cremer OL, van Dijk GW, van Wensen E, Brekelmans GJ, Moons KG, Leenen LP, Kalkman CJ (2005) Effect of intracranial pressure monitoring and targeted intensive care on functional outcome after severe head injury. Crit Care Med 33:2207-2213

F. B. Plötz (®) • M. Kneyber • M. van Heerde $\cdot$ D. Markhorst VU medical center, Pediatric Intensive Care,

Amsterdam, The Netherlands e-mail: fb.plotz@vumc.nl

Tel.: +31-20-4442413

Fax: +31-20-4443045 